\title{
Computational Approach for Discovery and Characterization of Cancer Driver Missense Mutations
}

ACS Spring 2020 Virtual National Meeting

$3 / 23 / 2020$

G. Andrés Cisneros @CisnerosRes

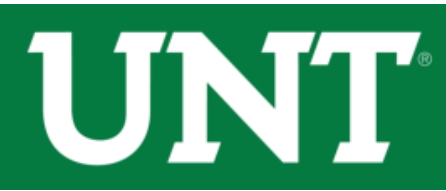

Nuniversity @i north teXAs

CASCaM

CKarmanos

CANCER INSTITUTE

Wayne State University 


\section{Acknowledgements}

\section{Group Members}

\section{Current}

Dr. Robert E. Duke

Dr. Sehr Naseem-Khan Erik A. Vázquez Mark A. Hix Emmett Leddin

J. Enrique Vázquez Madison Berger Ally Smith Miguel Espinoza Cory Shen Krithika Ravishankar

Linda Chelico (U. Saskatchewan) Penny Beuning (Northeastern U.) Robert Hausinger (MSU) Rahul Kohli (U. Penn) Jean-Philip Piquemal (Sorbonne U.)

Funding

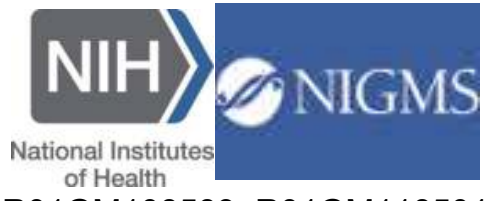

R01GM108583; R01GM118501

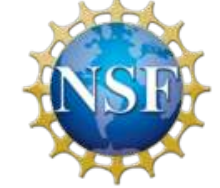

CHE-1856162

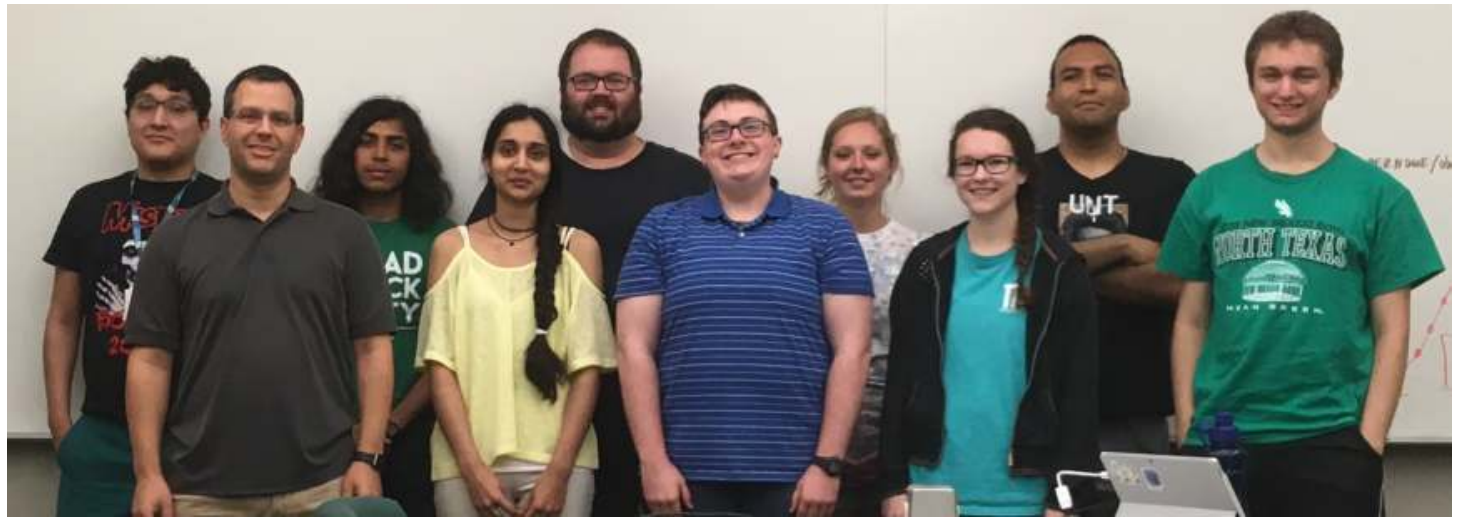

Alumni (contributing)

Dr. Alice Walker (Stanford) Dr. Pavel Silvestrov Dr. Dong Fang (Xtalpi)

Dr. Hedieh Torabifard (U of M) Dr. Rebecca Swett (Vertex) Dr. Hatice Gokcan (UNC) Dr. Eric Kratz (Continental)

\section{Collaborators}

Gregory Dyson (Karmanos) lannis Aifantis (NYU Med) Faruck Morcos (UT-Dallas) Tom Darden (OpenEye) Matt Allen (WSU)

\section{nVIDIA.}

Stas Groysman (WSU) Berny Schlegel (WSU) Judy Wu (U. Houston) Pengyu Ren (UT-Austin) Oleg Tsodikov (UKY)

Computing Time 


\section{Outline}

- Discovery and Characterization of Cancerassociated missense variants

- Characterization of DNA Polymerase cancer mutants

- DNA Polymerase $\lambda$ breast cancer-associated variant

- DNA demethylases

- ALKBH7 prostate cancer-associated variant

- APOBEC3H; lung cancer associated variant

- Characterization of cancer variant and prediction of rescue mutant 


\section{From Bioinformatics to Electronic Structure}

- New computational approach to uncover and characterize disease-associated mutations:

- Targeted search for missense mutations combined with statistical analysis

- Investigation of structural/functional/dynamical effects of cancer variants by Molecular Dynamics (MD) simulations and/or hybrid (QM/MM) simulations 


\section{DNA Polymerases}

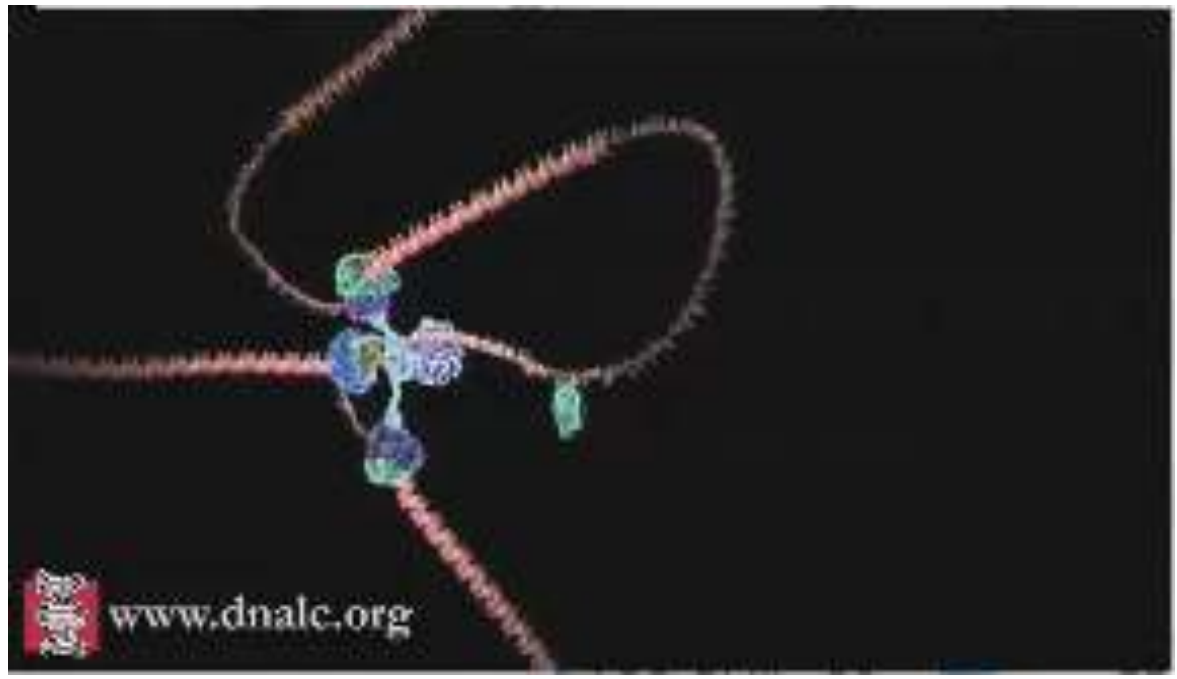

- Involved in DNA replication, repair and recombination

- Replicative polymerases synthesize DNA at $50 \mathrm{nb} / \mathrm{s}$ rate $(10 \mathrm{~h}$ for full human genome replication)

- 1 in 10 billion BP error rate

https://dnalc.cshl.edu/resources/3d/04-mechanism-of-replication-advanced.html

- QM/MM investigation of reaction mechanism of DNA Pold

- Predicted catalitically active " 2 nd Shell" residues around active site (GAC, et al, DNA Rep., 2008, 7, 1824)
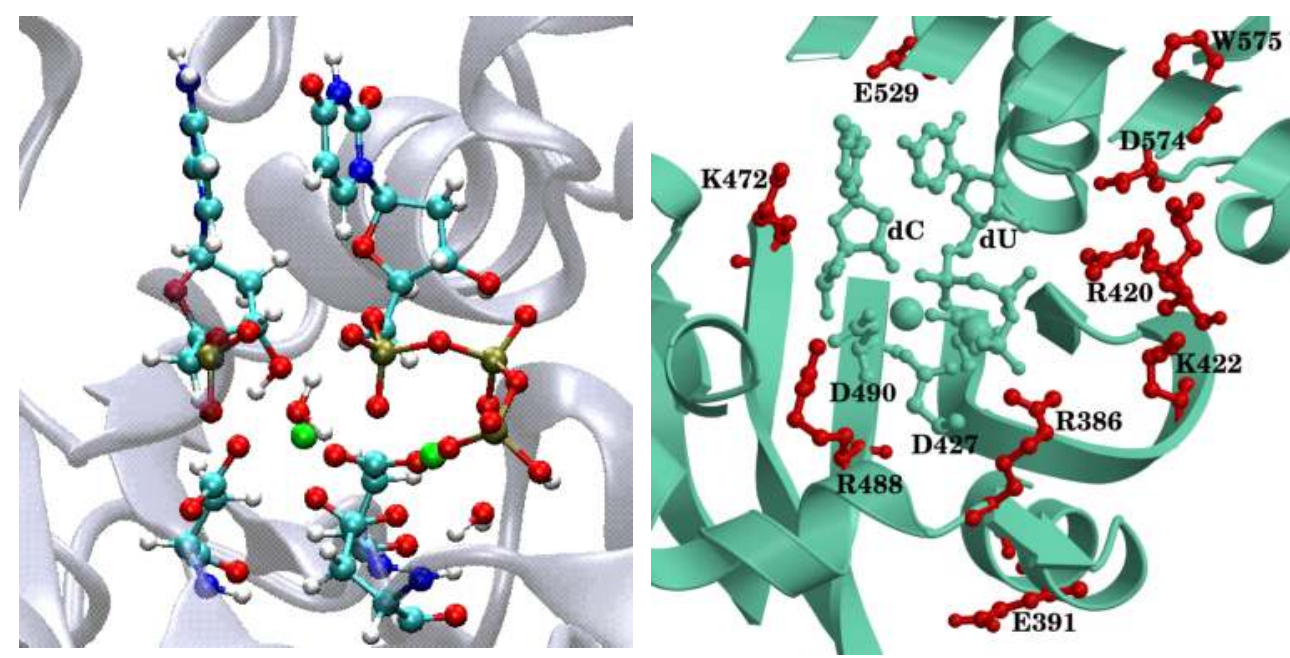

GAC, et al, DNA Rep., 2008, 7, 1824 


\section{Single Nucleotide Polymorphism (SNP) Analysis}

- Hypothesis: Individuals with SNPs on DNA polymerase genes that affect "2nd shell" catalytically active residues with a functional impact on the protein product are likely to have a predisposition toward cancer

- Approach: Develop an algorithm (and software) to search for SNPs on a single gene(s) of interest, ascertain statistical significance of SNPs $\rightarrow$ Hypothesis Driven SNP Search (HyDn-SNP-S); followed by computational characterization of structure/function/dynamics impact 


\section{Linking Phenotypes to Structures}

Cancer SNPs on DNA Pols

- Application of HyDn-SNP-S to search and characterize missense cancer SNPs on human DNA Pols
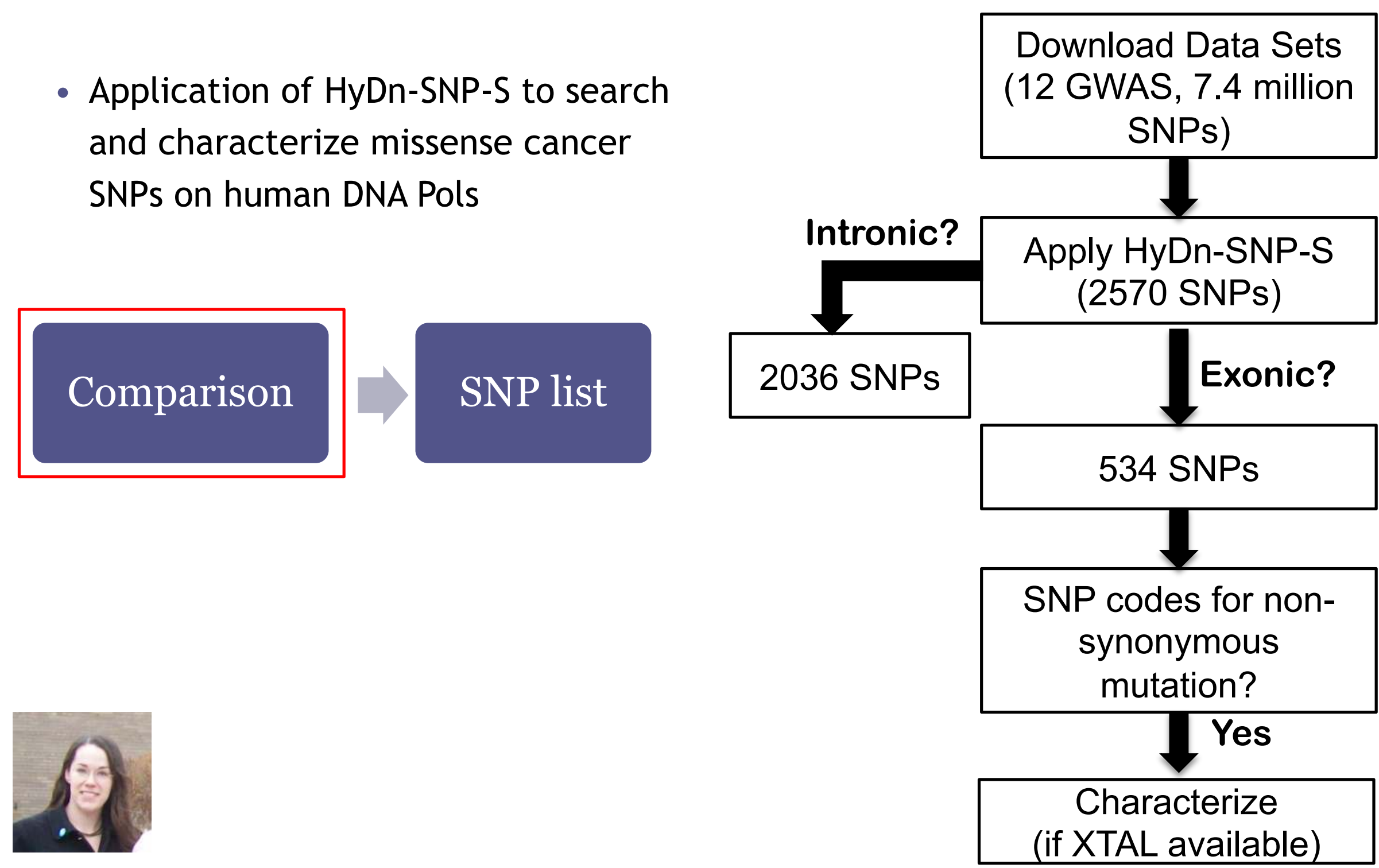

Swett R.J.., et al, DNA Rep., 2013, 12, 733 


\section{SNPs in DNA Pols}

\begin{tabular}{|c|c|c|}
\hline Polymerase & Mutations & Phenotypes \\
\hline Pol $\alpha 2$ & F548L, G592V & $\begin{array}{c}\text { melanoma, breast, pancreas, } \\
\text { prostate, }\end{array}$ \\
\hline Pol $\beta$ & $\begin{array}{c}\text { H51Q, K54Stop, } \\
\text { R137Stop, G144G, P242A, } \\
\text { Y296F }\end{array}$ & melanoma, prostate, \\
\hline $\mathrm{Pol} \Delta 2$ & $\begin{array}{c}\text { T436A, S412C, R166A, } \\
\text { Y54Stop }\end{array}$ & melanoma, prostate, \\
\hline Pol $\Delta 3$ & $\mathrm{~A} 215 \mathrm{G}, \mathrm{A} 124 \mathrm{~V}$ & melanoma, prostate, \\
\hline $\mathrm{Pol} \Delta 4$ & Q37R, R39S, R39G & melanoma, prostate, \\
\hline Pole3 & L7V & prostate \\
\hline Poln & $\begin{array}{c}\text { T478S,T478M, } \\
\text { S514A,Q524Q, D646V }\end{array}$ & melanoma, prostate, lung \\
\hline Pold & $\mathrm{R} 437 \mathrm{~W}, \mathrm{R} 438 \mathrm{~W}$ & $\begin{array}{c}\text { melanoma, breast, pancreas, } \\
\text { prostate }\end{array}$ \\
\hline
\end{tabular}

Swett R.J., et al, DNA Rep., 2013, 12, 733 


\section{R438W Affects Loop 1 Dynamics}

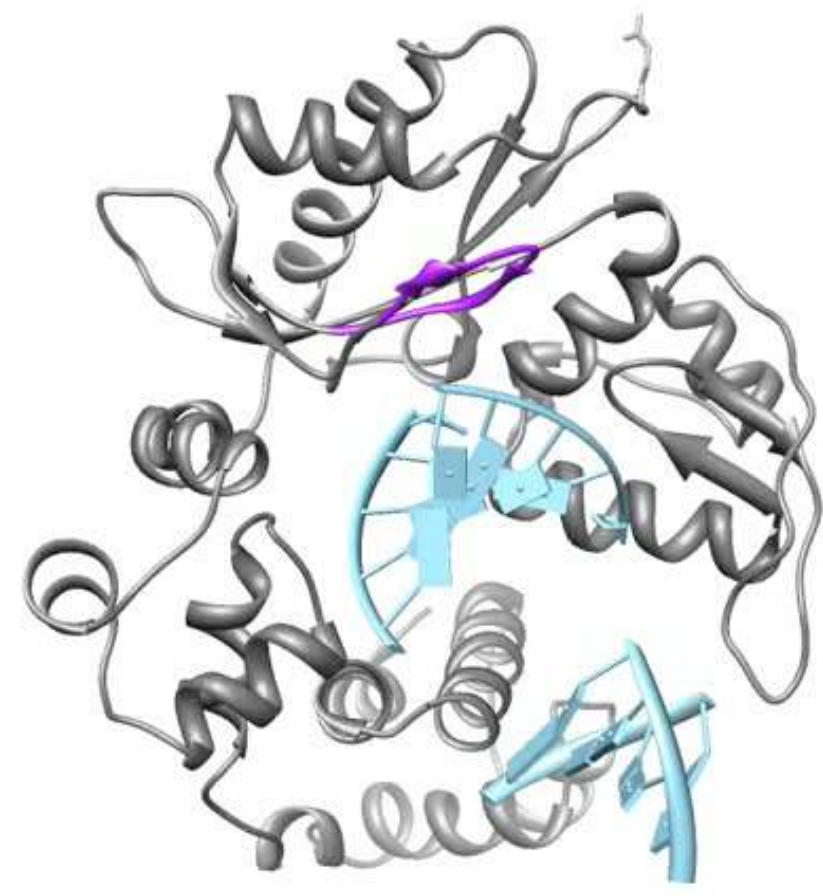

- Motion of loop 1 is correlated to site 438

- R438W alters loop 1 motion

- Loop 1 motion change in R438W may affect Pol $\lambda$ fidelity
- R438W is located near loop 1

- Loop 1 is critical for Pol $\lambda$ fidelity Bebenek et al., NAR, 38, 5419, 2010

- MD on 4 systems to study cancer variant effect

\begin{tabular}{|c|c|c|}
\hline Complex & WT & Mutant \\
\hline Pol $\lambda$-DNA & 1RZT & 1RZT R438W \\
\hline Pol $\lambda$-DNA-dNTP & 2PFQ & 2PFQ R438W \\
\hline
\end{tabular}

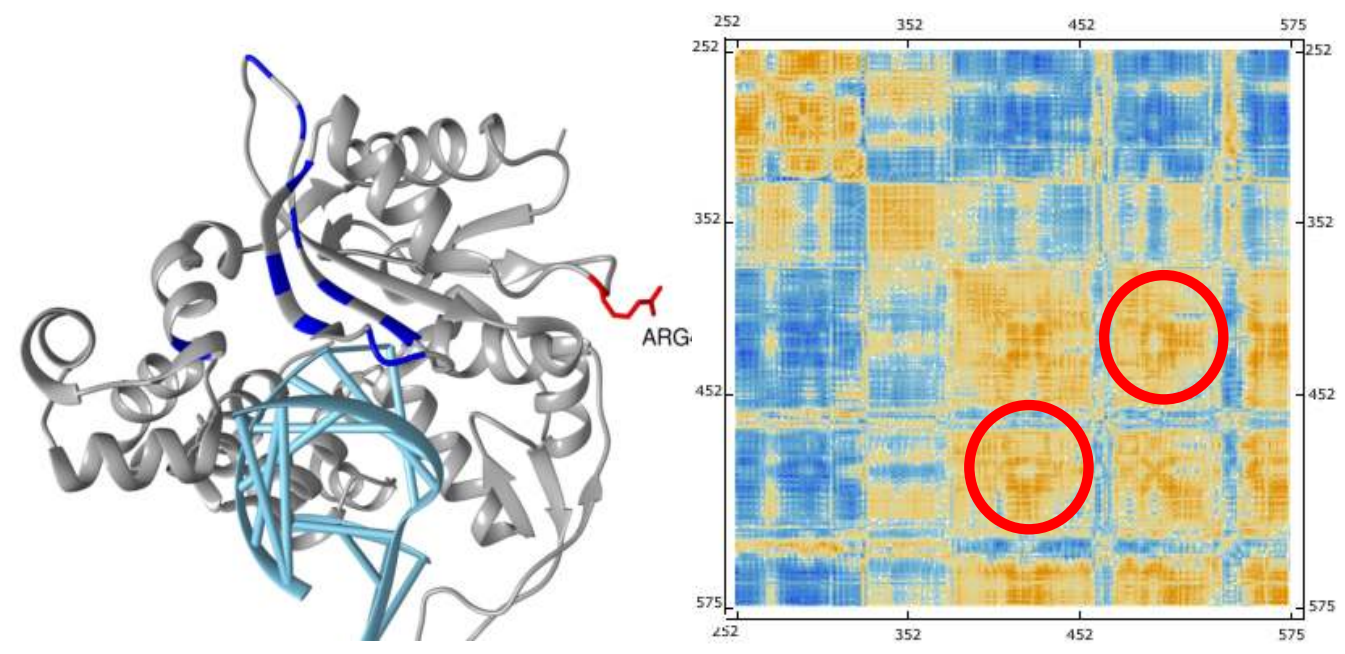

Swett R.J., et al, DNA Rep., 2013, 12, 733 


\section{R438W Confirmed as Breast Cancer Risk Factor}

\section{Molecular Cancer Research}

Home About Articles For Authors Alerts News

Estrogen Drives Cellular Transformation and Mutagenesis in Cells Expressing the Breast Cancer-Associated R438W DNA Polymerase Lambda Protein 


\section{AlkB Family Enzymes}

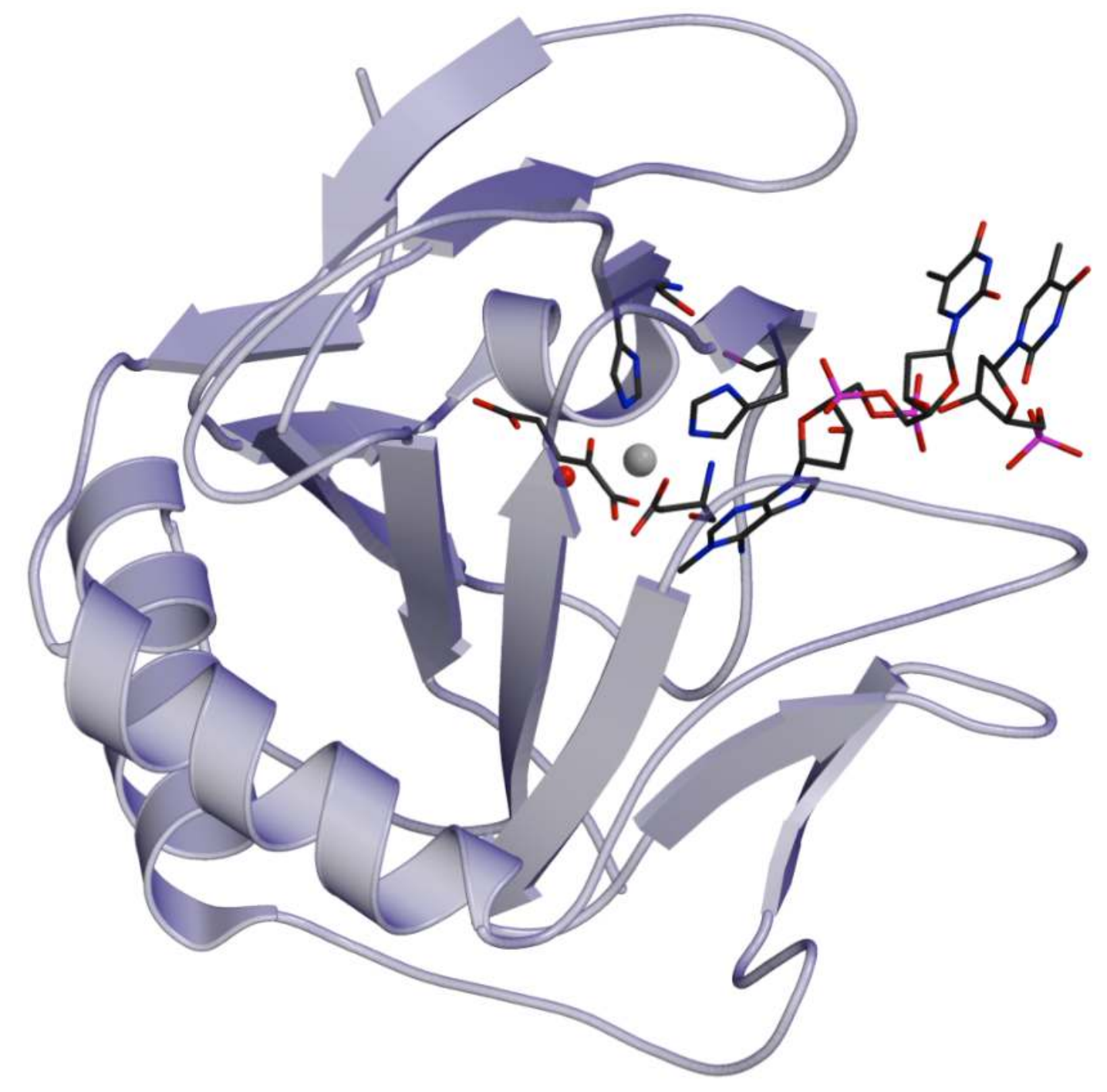

- In charge of dealkylating damaged nucleobases

- $\mathrm{Fe}(\mathrm{II}) / \mathrm{a}-$-ketoglutarate dependent

- Can act on different substrates: ssDNA, dsDNA, RNA, even some proteins

- Conserved active site motif

- AlkB (E coli) title enzyme, and 9 human homologues

Chengqi Yi et al., Nature, 2010, 468, 330 


\section{Cancer SNPs on AlkB family}

Are there any SNPs on AlkB enzymes that are correlated in a statistically significant manner to prostate cancer?

\begin{tabular}{|c|c|c|c|}
\hline SNP & Gene & $\begin{array}{l}\text { Intronic(I)/ } \\
\text { Exonic(E) }\end{array}$ & $\begin{array}{l}\text { Effect of } \\
\text { the } \\
\text { Missense } \\
\text { Mutation }\end{array}$ \\
\hline rs7160307 & $A L K B H 1$ & I & \\
\hline rs3751812 & FTO & I & \\
\hline rs6499653 & FTO & I & \\
\hline rs8044769 & FTO & I & \\
\hline rs7540 & ALKBH7 & $E$ & $\mathrm{R} 191 / \mathrm{Q}$ \\
\hline rs7193938 & FTO & I & \\
\hline rs9302652 & FTO & I & \\
\hline rs7190492 & FTO & I & \\
\hline rs8050136 & FTO & I & \\
\hline rs12447481 & FTO & I & \\
\hline
\end{tabular}

Walker A.R., Silvestrov, P. et al, PLoS Comp. Bio., 2017, 13, e1005345 


\section{Location of R191 w.r.t. Active Site}

- R191 is 22 Angstrom away from active site

- MD simulations on wild type (WT) and R191Q mutant with aKG and succinate bound to $\mathrm{Fe}(\mathrm{II})$

- 500 ns (in triplicate) for each system: AMBER14/ff12SB.

- MMGBSA to calculate change in cofactor/co-substrate binding enthalpy

- UV/Vis absorbance on WT and R191Q

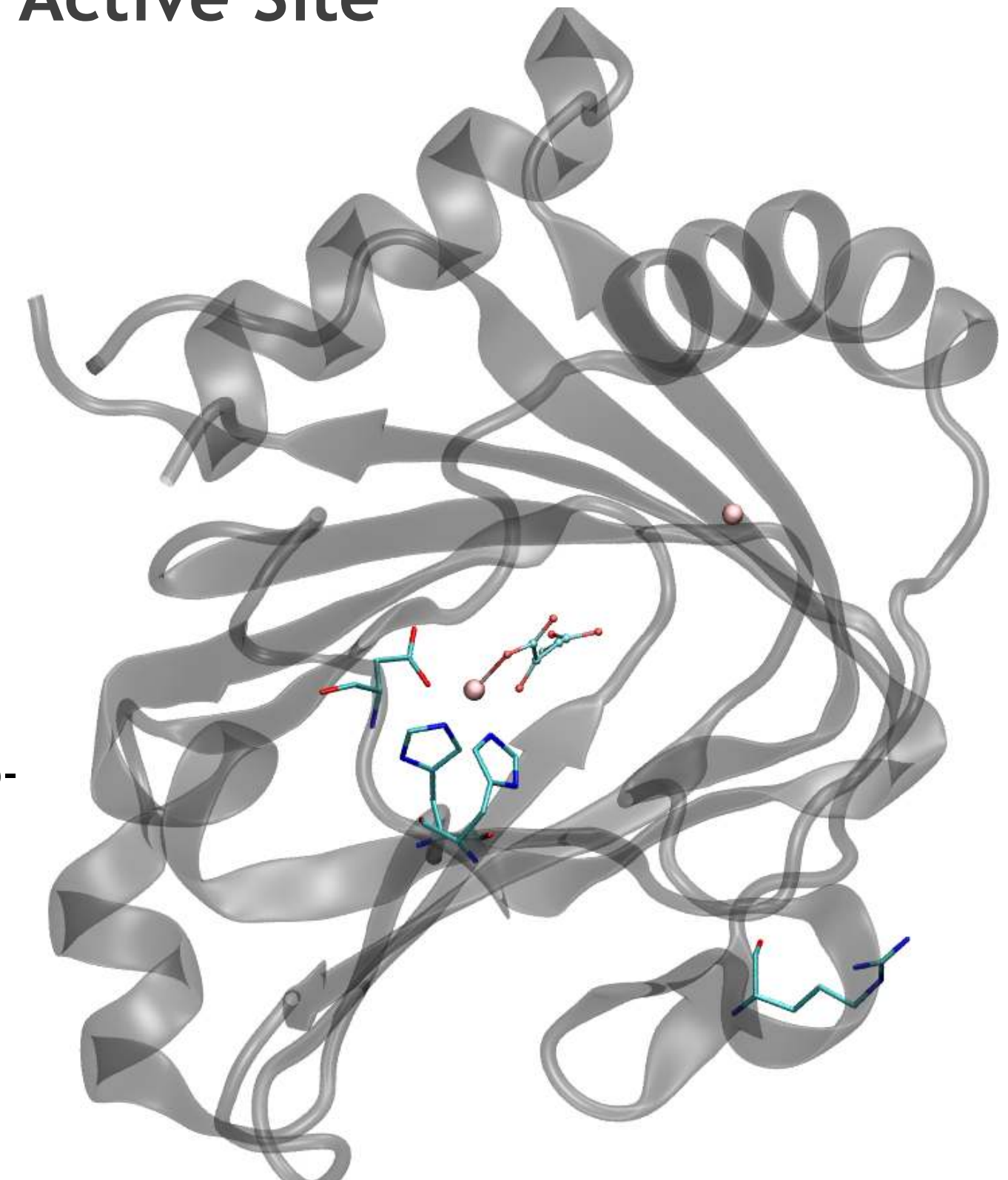

Walker A.R., Silvestrov, P. et al, PLoS Comp. Bio., 2017, 13, e1005345 


\section{Comparison of WT and R191Q Structure}

Gray: WT ALKBH7 Yellow R191Q ALKBH7

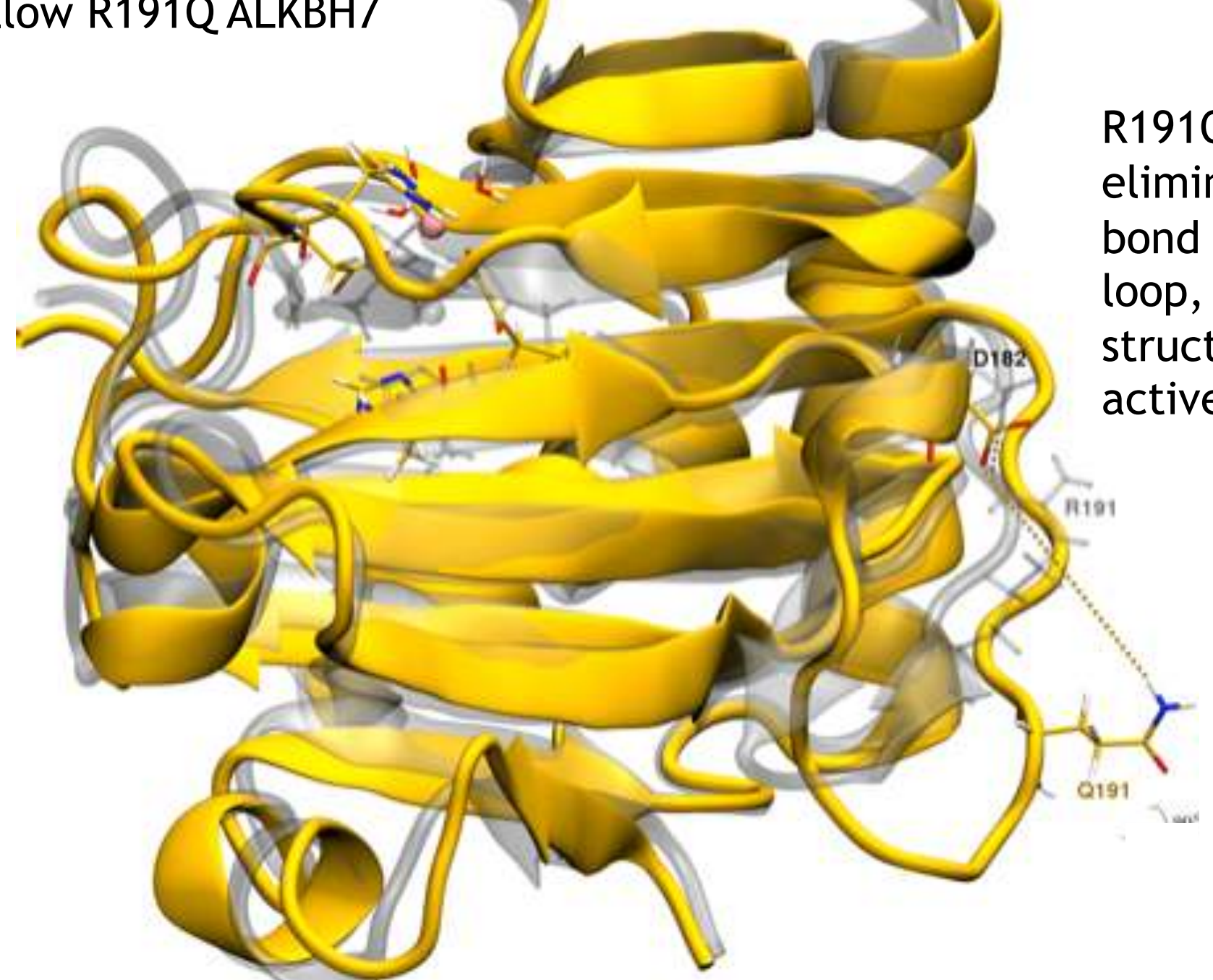

Walker A.R., Silvestrov, P. et al, PLoS Comp. Bio., 2017, 13, e1005345 


\section{Co-Factor/Co-Substrate Binding Energy (MMPBSA)}

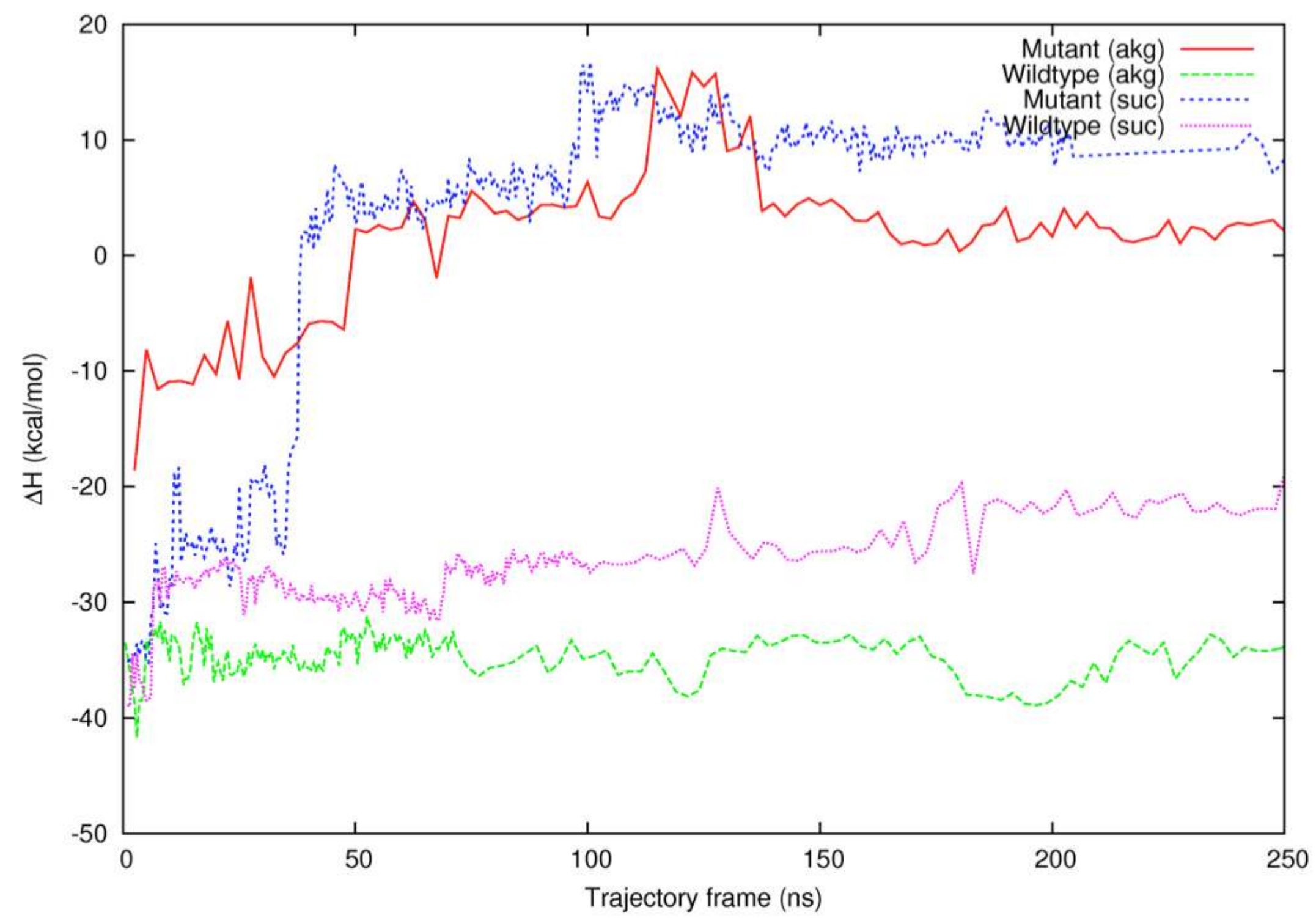

Walker A.R., Silvestrov, P. et al, PLoS Comp. Bio., 2017, 13, e1005345 


\section{Difference Absorption Spectra of ALKBH7}

\section{Wild Type}

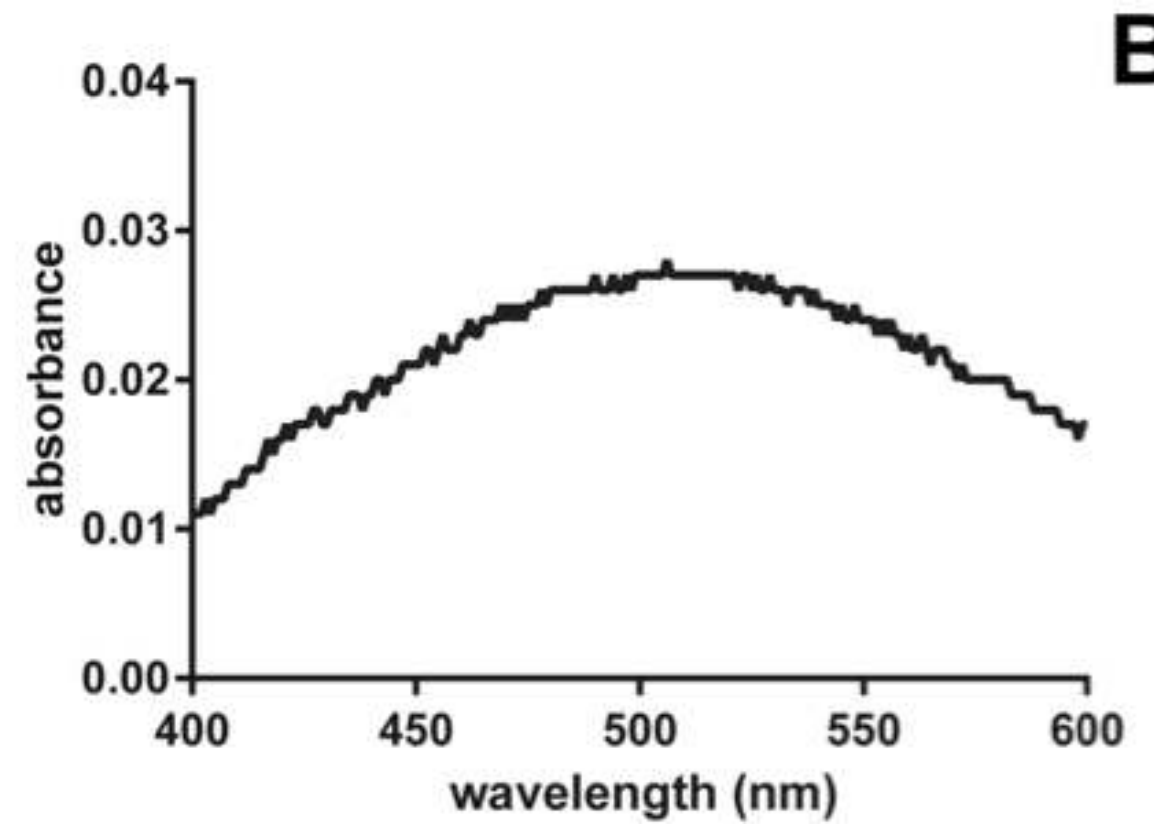

Data from Dr. T. Müller and Prof. R. Hausinger, Thanks to Prof. Z. Chen for ALKBH7 Plasmid

\section{R191Q Variant}

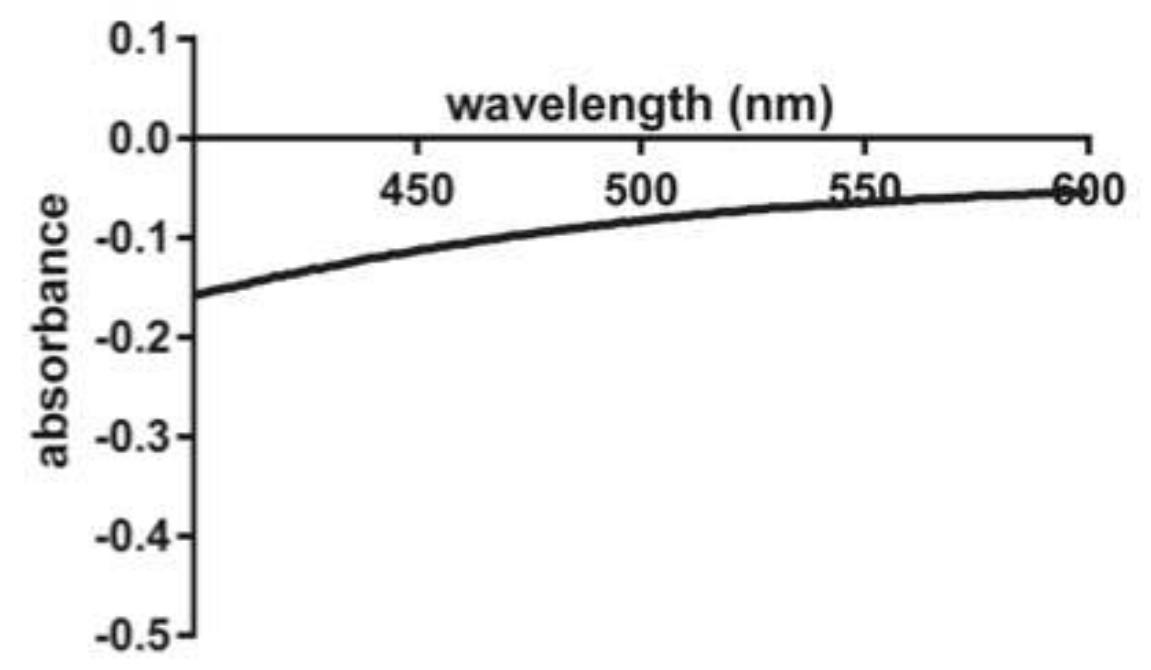

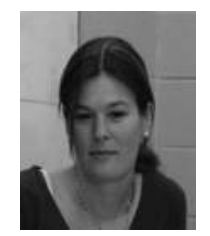

Walker A.R., Silvestrov, P. et al, PLoS Comp. Bio., 2017, 13, e1005345 


\section{HyDn-SNP-S on DNA Repair/Modification Enzymes}

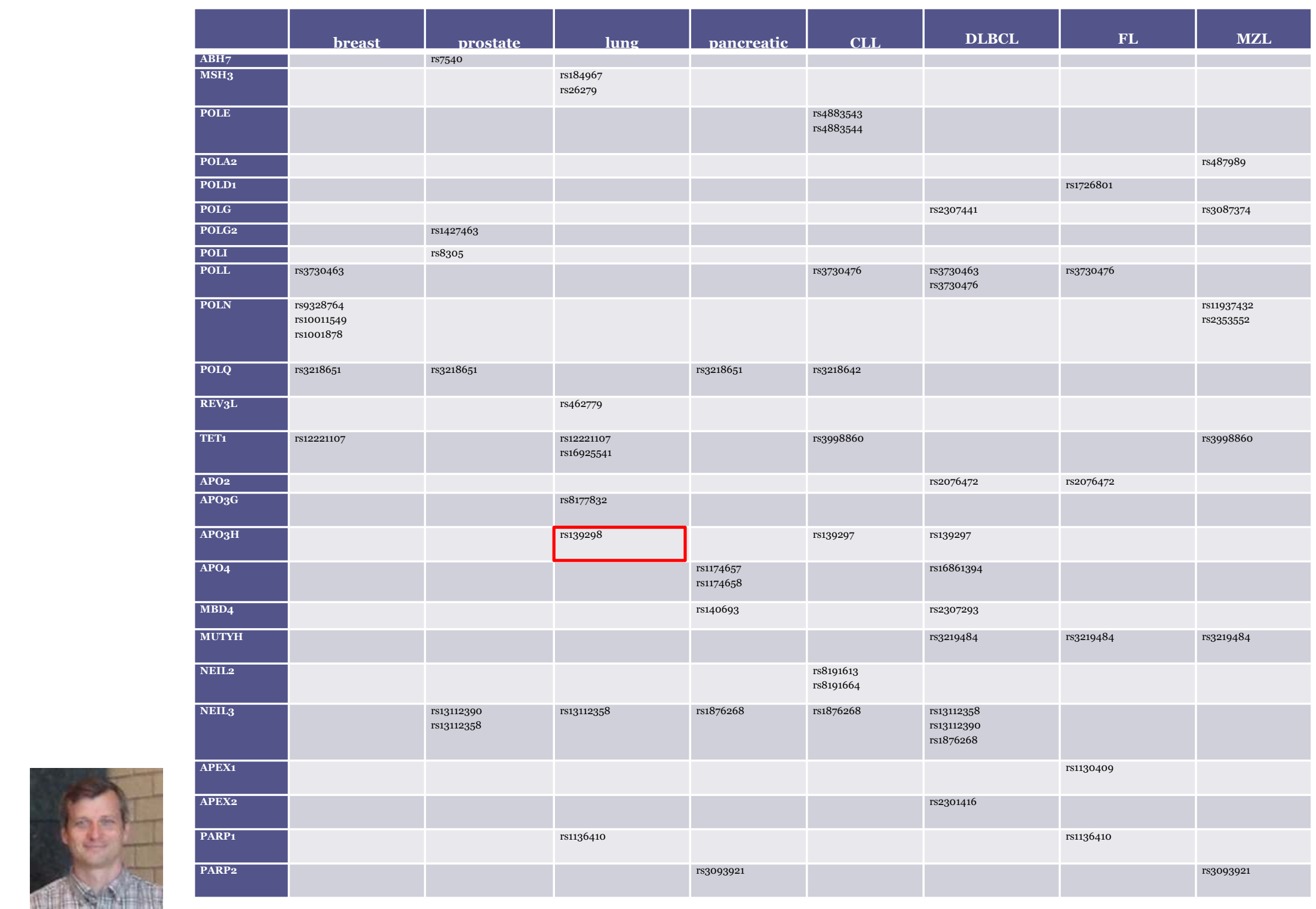

Silvestrov, P. et al, DNA Rep., 2018, 70, 10-17. 


\section{APOBEC $3 \mathrm{H}$}

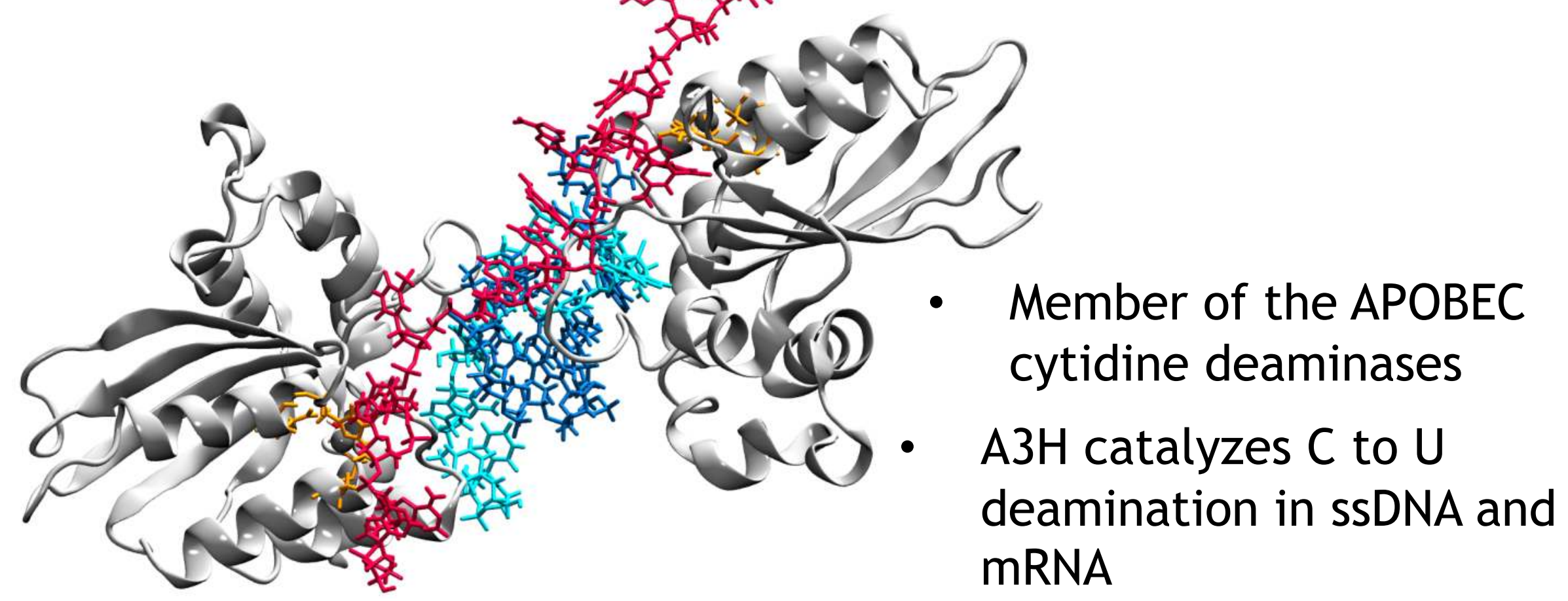

- Responsible for antiretroviral activity against HIV-1

- HyDn-SNP-S uncovered A3H K121E variant related to lung cancer

- MD on en WT A3H and K121E, K117E and K121E/K117E A3H

- 200 ns (in triplicate) for each system: OpenMM/ff12SB 


\section{K121E Forms New H-Bond Networks}

a)

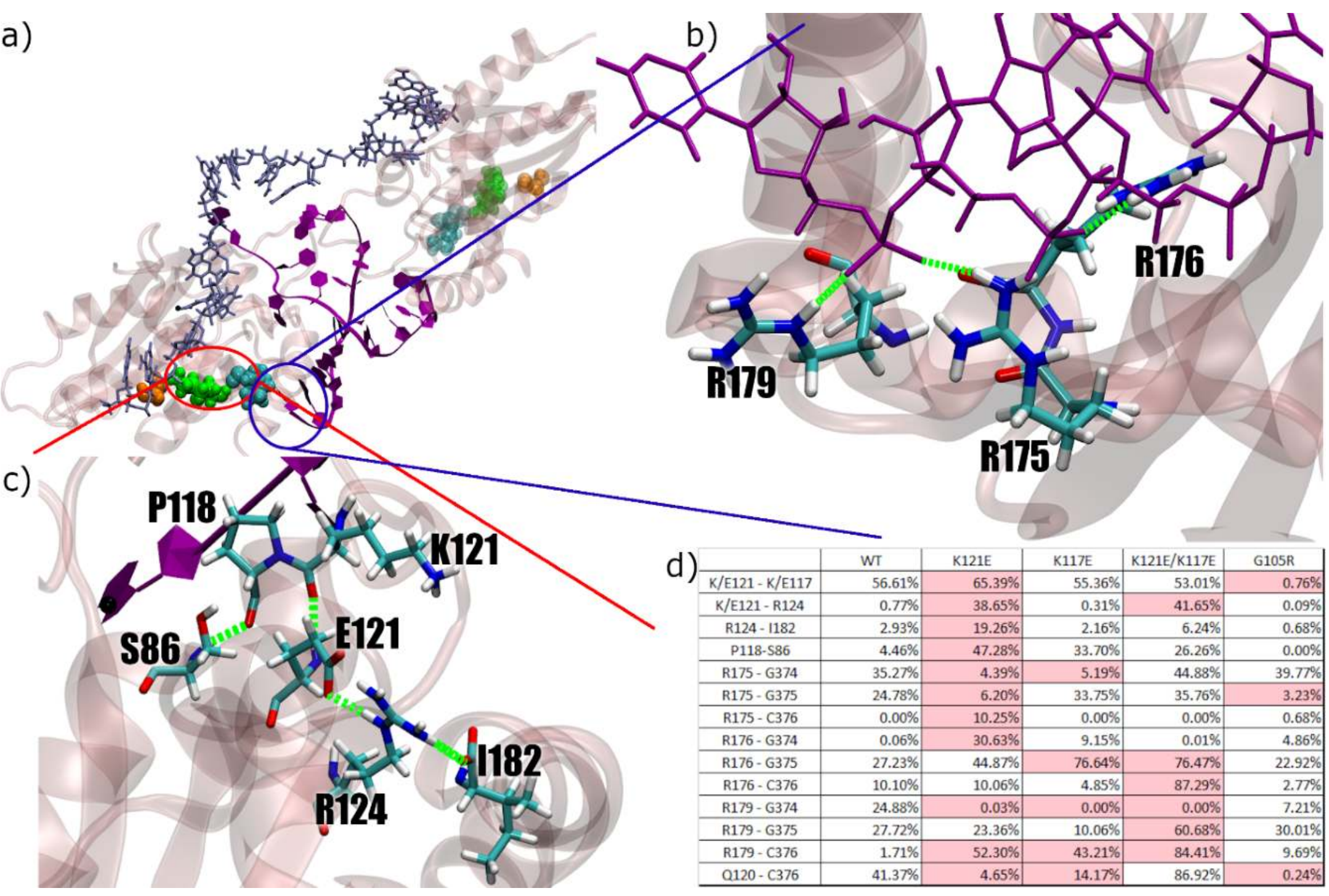

Hix, M.A., et al, https://doi.org/10.1101/2020.02.28.970509, 2020. 


\section{$\mathrm{K} 117 \mathrm{E} / \mathrm{K} 121 \mathrm{E}$ rescues; K117E stabilizes dimer}

a) $\mathrm{K} 121 \mathrm{E}$

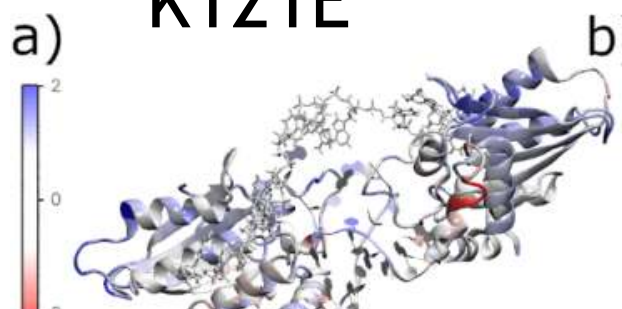

d)

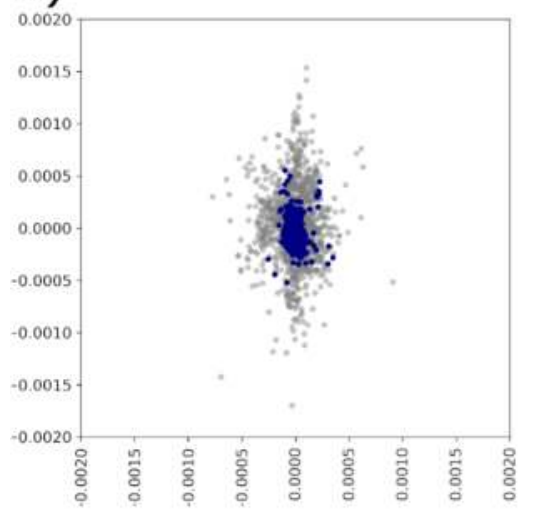

g)

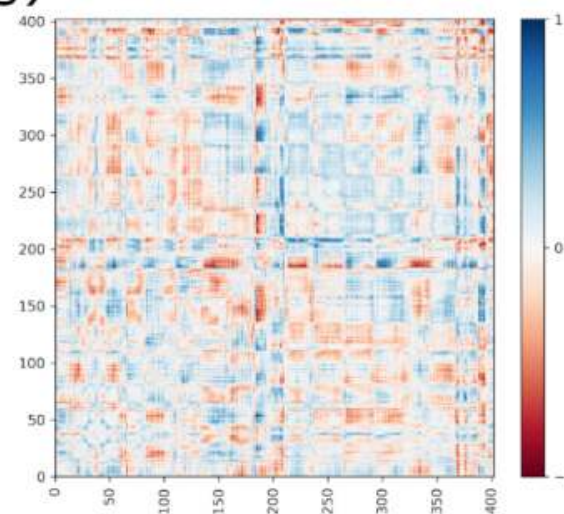

b) K117E/K121E

e)

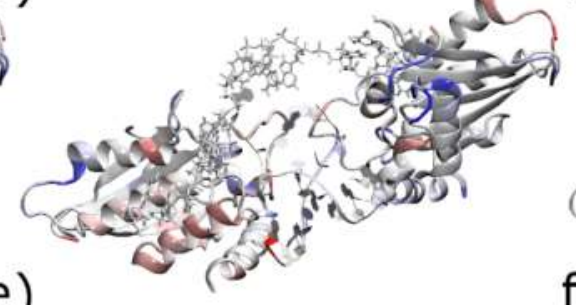

e)

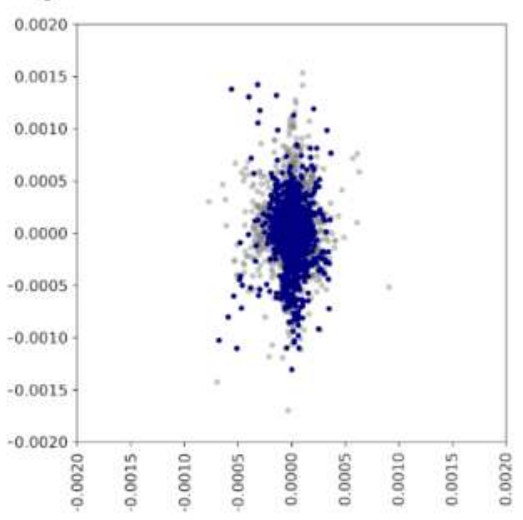

h)

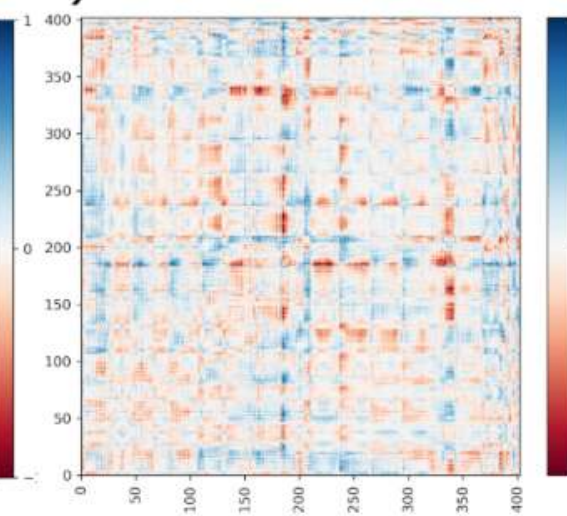

c) K117E

Diff. RMSF w.r.t. WT

f)

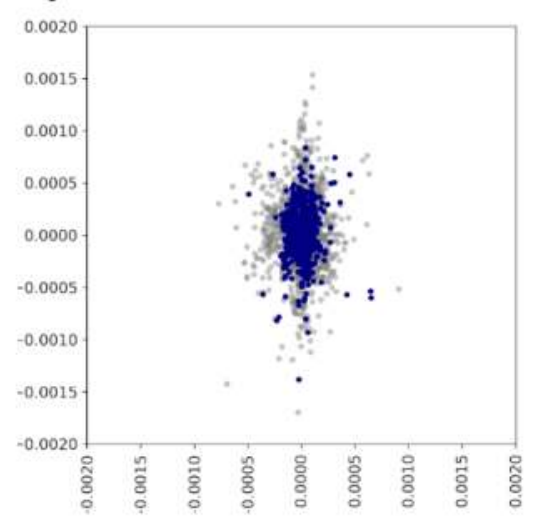

i)

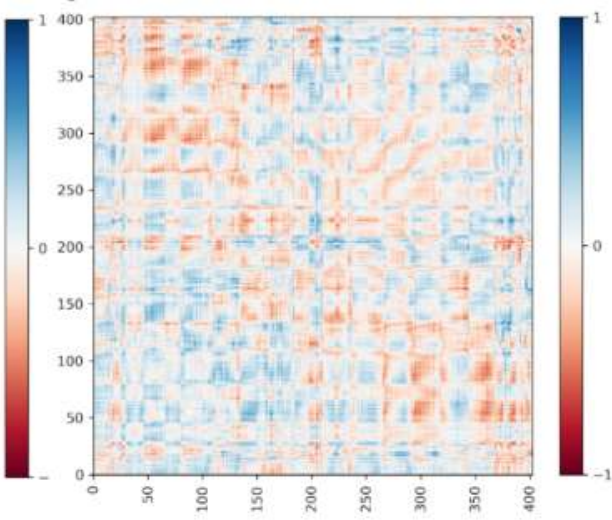

PCA (gray=WT)

Diff. Correlation 


\section{Experimental Results}

Expression

Transient expression in 293T Cells

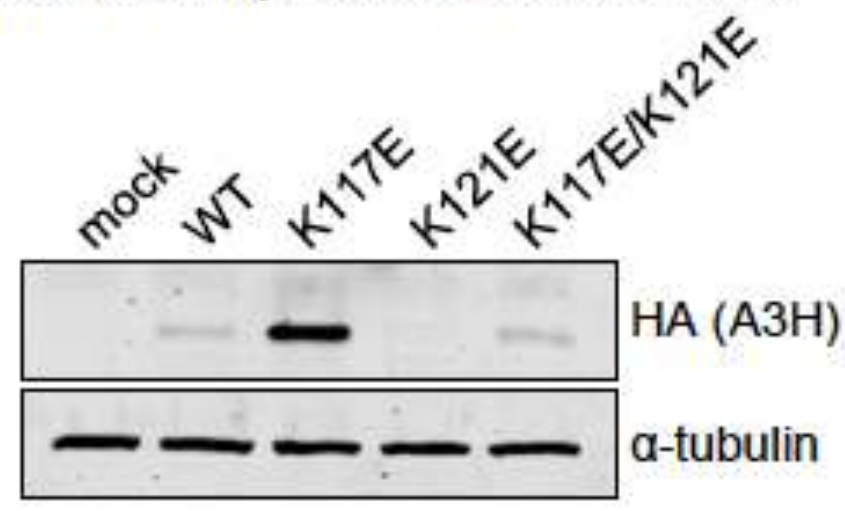

Hap I

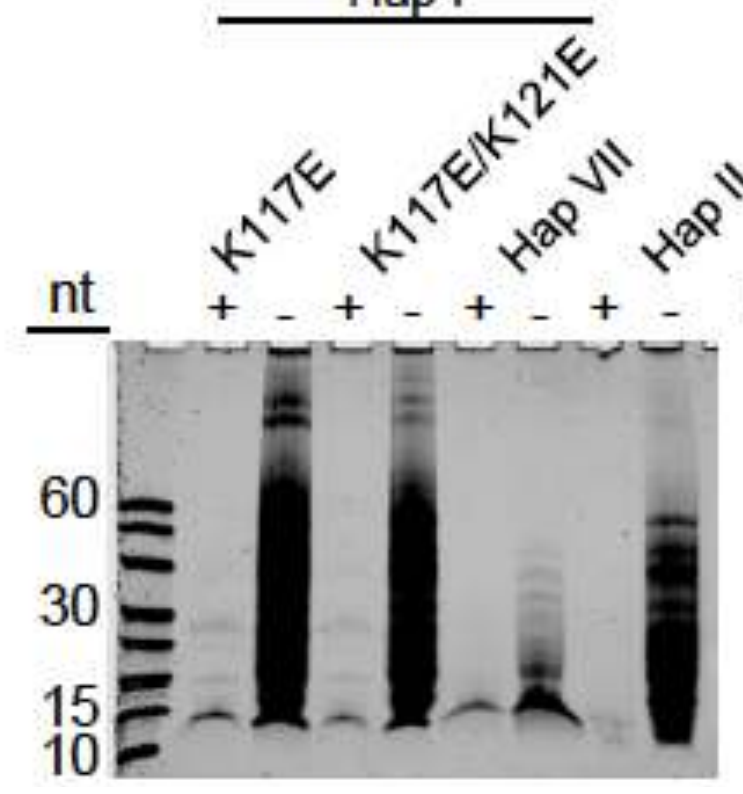

Activity

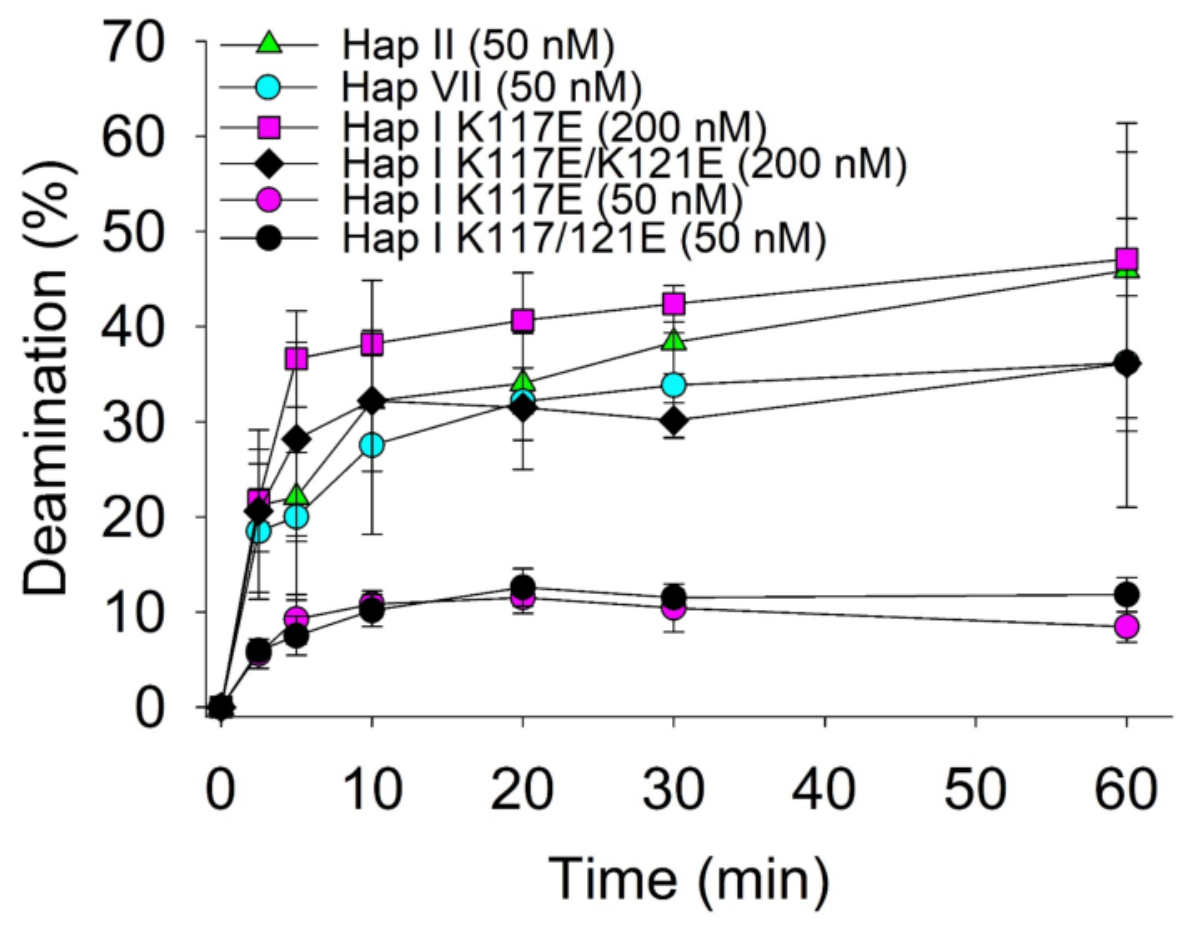

\section{Dimerization}

Data from Prof. L. Chelico, B. Flath, and L. Wong 


\section{Experimental Results}

$\gamma \mathrm{H} 2 \mathrm{AX}$ foci
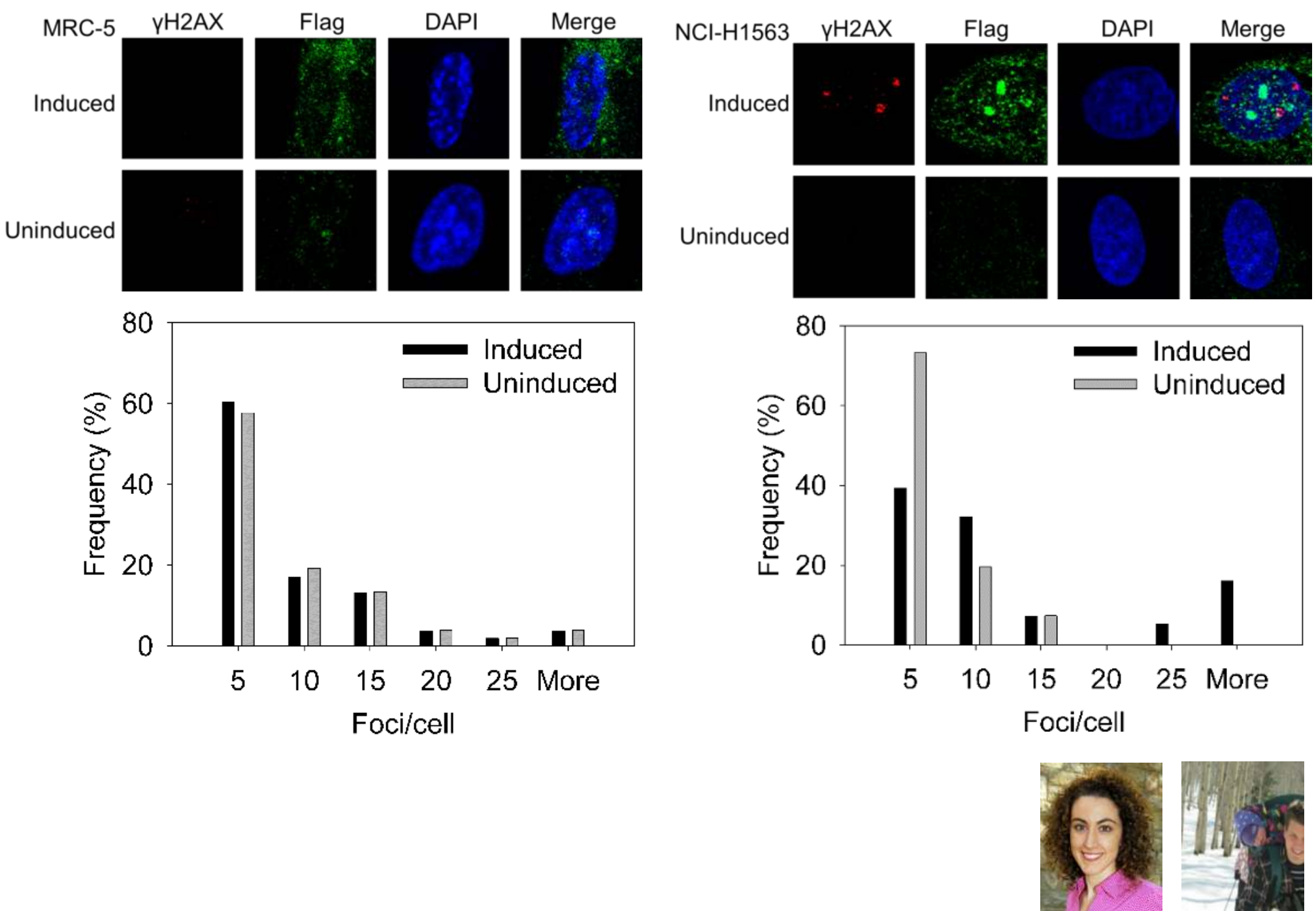

Data from Prof. L. Chelico, B. Flath, and L. Wong 


\section{Summary}

- HyDn-SNP-S: New SNP mutant discovery and characterization approach using atomistic simulations

- Uncovered and characterized various missense mutations on DNA Pol $\lambda$ associated with breast cancer

- ALKBH7 prostate cancer mutations results in ALKBH7 R191Q variant, affects co-substrate binding

- $\mathrm{A} 3 \mathrm{H} \mathrm{K121E}$ is associated with lung cancer, destabilizes the structure and abolishes catalytic activity

- Active $\mathrm{A} 3 \mathrm{H}$ coupled with $\mathrm{A} 3 \mathrm{~B}$ exhibit increased DS breaks, elimination of $\mathrm{A} 3 \mathrm{H}$ gives "just right" mutation rate 


\section{Acknowledgements}

\section{Group Members}

\section{Current}

Dr. Robert E. Duke

Dr. Sehr Naseem-Khan Erik A. Vázquez Mark A. Hix Emmett Leddin

J. Enrique Vázquez Madison Berger Ally Smith Miguel Espinoza Cory Shen Krithika Ravishankar

Linda Chelico (U. Saskatchewan) Penny Beuning (Northeastern U.) Robert Hausinger (MSU) Rahul Kohli (U. Penn) Jean-Philip Piquemal (Sorbonne U.)

Funding

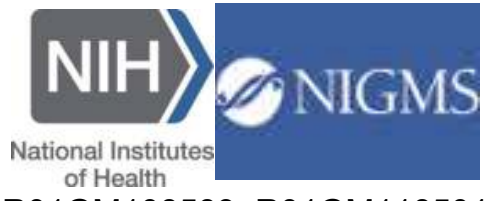

R01GM108583; R01GM118501

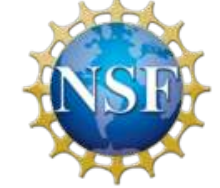

CHE-1856162

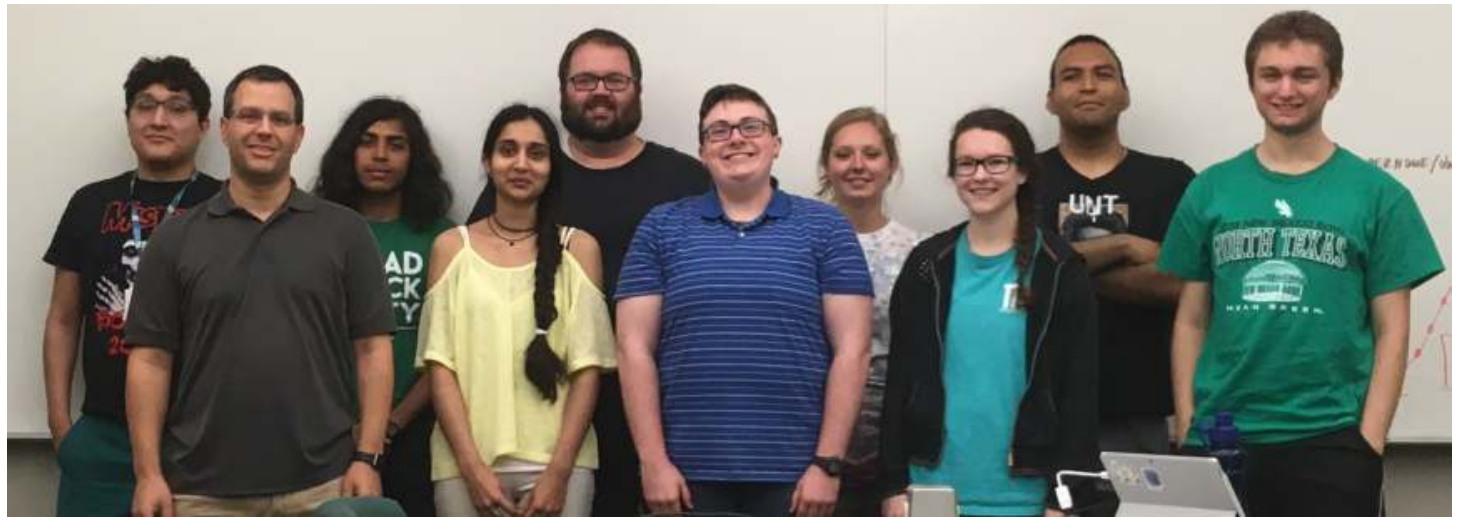

Alumni (contributing)

Dr. Alice Walker (Stanford) Dr. Pavel Silvestrov Dr. Dong Fang (Xtalpi)

Dr. Hedieh Torabifard (U of M) Dr. Rebecca Swett (Vertex) Dr. Hatice Gokcan (UNC) Dr. Eric Kratz (Continental)

\section{Collaborators}

Gregory Dyson (Karmanos) lannis Aifantis (NYU Med) Faruck Morcos (UT-Dallas) Tom Darden (OpenEye) Matt Allen (WSU)

\section{nVIDIA.}

Stas Groysman (WSU) Berny Schlegel (WSU) Judy Wu (U. Houston) Pengyu Ren (UT-Austin) Oleg Tsodikov (UKY)

Computing Time 